\title{
SPACE NEEDED TO MAKE A CITY SUSTAINABLE AND NECESSARY CHANGES TO REACH IT: THE CASE OF GERMANY
}

\author{
UDO DIETRICH \\ REAP Research Group (Resource Efficiency in Architecture and Planning), \\ HafenCity University Hamburg, Germany
}

\begin{abstract}
A city concentrates humans, apartments, services, factories, and other facilities. The city is in permanent exchange with its surrounding, receiving food, energy, water, materials and others while delivering products, formation etc. If that whole process would run in a way that it can run in the same way for all future generations, the city would be a sustainable one. As a consequence, it is not adequate to regard only the city scale; the city has to be investigated together with its surrounding. This paper investigates what a sustainable city could be. Starting from the human needs a liveable city is sketched regarding its density and internal organisation, land use, buildings, and their arrangement. The potential of harvesting renewable energies and food per land unit is estimated. The present demand leads to an immense need of land to cover it. To reach sustainability, three different strategies are possible: (a) keep the demand like it is; (b) reduce the demand by increasing efficiency; or (c) reduce the demand by a change of the lifestyle; and cover for (a) to (c) the remaining demand with renewable systems. The highest potential for strategy (b) is in the building sector (refurbishment) and transportation (electrical machines), (c) is touched for food production (widely vegetarian nutrition). Assuming that these changes are already realized, the demand of land for renewable production of energy and food is determined based on corresponding literature and statistical data. For Germany, the need of land exceeds the available land still by $50 \%$. Strategies (a) and (b) led to a big improvement, but without strategy c) the target cannot be reached. That confirms the assumption that the available land for food production and harvest of renewable energies could prove oneself as another limited resource that might be even the dominant one.

Keywords: sustainable city, urban density, transportation network, harvesting renewable energies, space needed for food production and harvest of renewable energies, lifestyle, strategies to transfer cities into sustainable ones.
\end{abstract}

\section{INTRODUCTION}

The inhabitants of a sustainable city enjoy spending their lives in a liveable surrounding but with an environmental impact that does not negatively influence the same wish for the following generation(s). These are the first two columns of sustainability, social and environmental; the third one economical is of basic importance but not further regarded in this paper. It is task of our society and policy to make the necessary changes financeable.

It is known that our cities are more or less still far from being sustainable. For the necessary transformation, in minimum much as possible, we have a time frame of only few decades (2050). In literature many different visions of what it should be are to find [1], diverse cities around the planet started with practical initiatives.

The general concept is that the city concentrates of course humans but also apartments, services, factories and other facilities. The city is in strong exchange with its surrounding. The city needs (raw) materials, water, food, energy and others; in return products, education etc. are delivered. Currently that exchange is out of balance in regard to two aspects [2]:

- The needs of the city exceed the potential of the near surrounding to deliver. 
- The exchange is widely not concentrated on the local surrounding but covering the whole planet. That consequence of too cheap transportation contributes worldwide to non-sustainable development.

Most of the literature dealing with sustainable cities is concentrating on the city itself and not including the fact that self-sufficiency can be reached only on the bigger scale city plus surrounding.

This paper deals with both aspects. First the type of city that would deliver best liveability is described in density and organisation. Then the corresponding surrounding is described in land use and size. That matter is very complex; the description will be based on rough estimations and literature. But it will show the dimension of the necessary changes as well as their direction. A comparison with the existing situation will make it further evident.

\section{THE LIVEABLE CITY}

A city that has no environmental impact but is not liveable would not be a successful solution of the problem. The highest priority is given to the creation of a liveable city but together with the (good) hope that a liveable city delivers also best preconditions for a city with minimized environmental impact.

\subsection{Density and internal organisation}

A liveable city shall be oriented to pedestrians and cyclists. A pedestrian expects basic services like a bakery, next public travel station in a distance that can be reached inside of a 5 minutes' walk or 3-500 $\mathrm{m}$. To find really a shop to buy a newspaper or some bread, a certain urban minimal density is necessary (how many clients' needs the bakery to survive - all these clients must have their apartments $500 \mathrm{~m}$ around the bakery; out of this the urban density can be calculated). In Cording [3] the value of 100 inhabitants per hectare (inh/ha) is cited for a liveable neighbourhood.

A minimal urban density is also a precondition for an efficient public transportation system. Investigations in Newman and Kenworthy [4] and Lefèvre [5] indicate as threshold about $50 \mathrm{inh} / \mathrm{ha}$, better $100 \mathrm{inh} / \mathrm{ha}$. These values refer to the whole metropolitan region, the inner part of a city will have higher densities, the outskirts lower ones. The inner part of (widely as very liveable accepted) Paris has the highest density of all European cities with $210 \mathrm{inh} / \mathrm{ha}$ but the metropolitan region has only about $60 \mathrm{inh} / \mathrm{ha}$. For better comprehension for all further investigations in Sections 2 and 7 an urban density of $100 \mathrm{inh} / \mathrm{ha}$ is assumed.

It can be seen that social criteria (liveability) and environmental ones (public transportation instead of car oriented) are going hand in hand. Further conclusion is that for further development extension of the cities (and urban sprawl) should be avoided but further densification inside of the existing cities prioritized to reach higher densities.

The organization of the street network and the pedestrian routes should be developed in a way that humans enjoy walking in it. That follows two basic principles:

- The network should often deliver the possibility to decide between different possibilities to continue, left, right or straight forward. Such nodes should be offered once per minute (each $100 \mathrm{~m}$ ) by the network, but partly still often with separations each 15, 30, $60 \mathrm{~m}$ by supplementary nodes only for pedestrians [6].

- The network should deliver sufficient elements of orientation, each 1-200 m (with a walk of in max two minutes all uncertainties are overcome, the next point of 


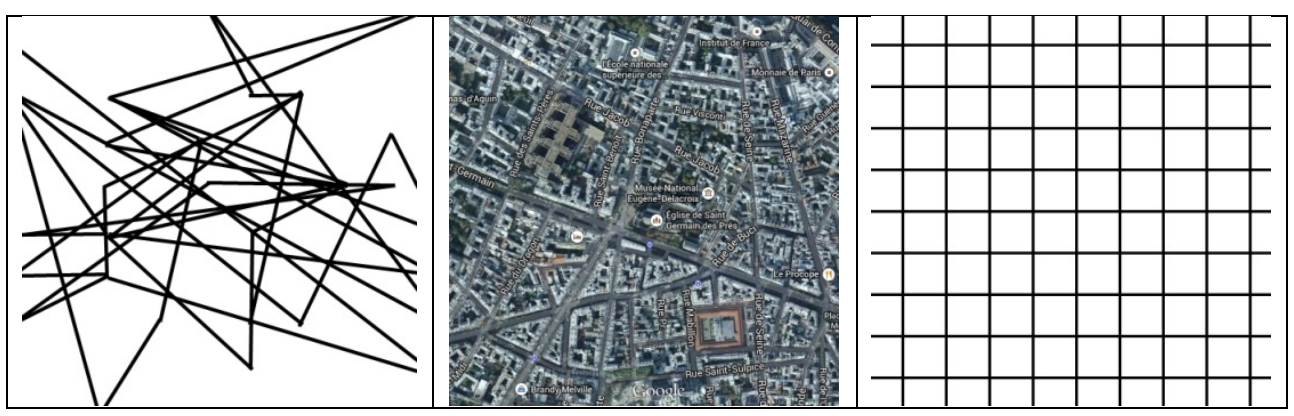

Figure 1: Three different types of pedestrian networks. In a chaotic one (left, made with a random number generator) one would feel lost. Also in a completely ordered one (right) there is no knowledge of being where (lack of reference points). The picture in the middle shows a section of highly walkable Paris SaintGermain with a lot of small streets and a few bigger streets for orientation [8].

orientation is found). A network that is too ordered would not offer enough orientation; in a chaotic grid the pedestrian would get lost (Fig. 1). The best organisation of the grid would be something between order and chaos [7].

The type of network that corresponds best to both criteria would be one with streets and routes in different width's (hierarchies) that could be clearly differentiated, it follows a Pareto distribution [9]: a few big, central arteries, a medium number of medium distributers and a high number of small and smallest streets forming a very fine network (Fig. 1).

The internal organisation of the network formed by streets and pedestrian/cycling routes is a precondition for walkability. There are decisive further aspects to fulfil that people feel really invited to walk, like sufficient width of sidewalks, clear separation of traffic modes with different velocities (car/pedestrian) etc.; corresponding rating systems describe these indicators [10]. But this is not in the centre of the topic of that paper and not further regarded.

\subsection{Land use}

To satisfy human needs people need to meet and recover open spaces in their city. To reach big parks and other facilities (stadium etc.) a journey of 30 to $60 \mathrm{~min}$ is accepted, they will be located at different places around the city. But besides of that people need for short stay and communication smaller units in the direct neighbourhood (places, pocket parks, public terraces etc.). Semi-public (secondary) territories are dedicated to a defined and limited group of persons (like a house community, sports club etc.). The distribution of these spaces should follow again a Pareto distribution: a few big, central units, more of middle sized (plaza mayor) and a lot of a small sized ones - that guarantees also that everybody will find offers in direct neighbourhood. For all these public and semi-public open spaces, a total area of 12 to (better) $20 \mathrm{~m}^{2} / \mathrm{inh}$ is recommended [3]. Together with the assumed $100 \mathrm{inh} / \mathrm{ha}$ these are 1,200 to $2,000 \mathrm{~m}^{2}$ and thus 12 to $20 \%$ of the area of the city.

Other 10 to $15 \%$ are necessary for central units like hospitals, schools, supermarkets, administration, culture, religion, etc. [11]. For circulation and parking further 25 to $35 \%$ of the area are used, industries fill another 20 to $25 \%$ of the area [11]. 
All together are already 60 to $80 \%$ of the area allocated to open spaces, central units and industries. Only the remaining space can be filled with buildings. A major part of these buildings will be used as apartments but a certain part (about $3.5 \mathrm{~m}^{2} / \mathrm{inh}$ [11]) should be reserved for retail and small services (kindergarten, dentist, bakery, cafe, restaurant etc.), they will be concentrated in the ground floors. With this offer, about in minimum $10 \%$ percent of the inhabitants could find their workplace in the own quarter [12], the corresponding mixed use reduces daily transfer inside of the city and invites inhabitants to stay inside of the quarter.

\subsection{Buildings and their arrangement}

In German cities each inhabitant has an apartment area of about 35 to $40 \mathrm{~m}^{2}$ available. With $100 \mathrm{inh} / \mathrm{ha}$ the total net floor area of apartments would be 3,500 to $4,000 \mathrm{~m}^{2}$. A factor of two can roughly be assumed between net and gross floor area (stairs, walls, public floors etc.) leading to a demand of 7,000-8,000 $\mathrm{m}^{2}$ gross floor area. Supplementary the area for retail and little services would need $350 \mathrm{~m}^{2}$ net and $700 \mathrm{~m}^{2}$ gross floor area. Together with the assumption that we can fill about $3,000 \mathrm{~m}^{2}$ with buildings, this rough estimation leads to an average number of storeys of three. That is a good message, the threshold where the technical effort (fire protection, elevators etc.) and energy demand (sealed facades and mechanical ventilation because of wind pressure etc.) jumps to a high level is at about five to six storeys - we are not obliged to construct sky-scrapers.

In a neighbourhood with three to six storey-buildings the area for retail and little service would comprise about one third to a quarter of the ground floor area, giving still space for apartments also on ground level.

Apartments should have a very good access to daylight and deliver an attractive view out of the window. It is known that areas of usage are still in daylight until a depth that corresponds twice the room height, with a height of 2.7 to $3 \mathrm{~m}$ that leads to an alighted area until about $6 \mathrm{~m}$ depth. Daylight from the sky reaches a building from all sides, with windows in opposite facades and a central part (floor, bathroom, kitchen etc.) in the building's core the recommended building depth is about 14 to $16 \mathrm{~m}$.

For good daylight access buildings should not shade each other and not block the way from the light source sky through the windows into the apartments. Optimal would be a building distance that is in minimum twice the building's height - but with that the available area can't be filled with enough apartments. As a compromise the building distance should be - wherever possible - in minimum equal to the building height; that ensures in minimum for the upper two third of the apartments good conditions.

The classical building block structure fulfils best all these requests. It guarantees a high urban density, the highest daylight access, offers internal courts as private and semi-public territories, quiet back sides for sleeping. The continuing facades along the streets deliver good orientation and identity for a walking person. The inner part of Paris is an example for such a structure (see Fig. 1) but similar quarters are to find in all big European cities. That statement may sound personal and subjective but a view to the city map and the quarters with the highest rents (as an indicator for attractiveness) shows that such quarters are preferred.

\section{WHAT WE NEED FOR DAILY LIFE - ENERGY AND FOOD}

In MacKay [13] the energy demand of an average middle European inhabitant is investigated and assessed. To facilitate the task and results presentation, the demand per day and inhabitant was used. Assessed is the end-energy demand, not the primary energy 
Table 1: Current energy demand of an average middle European inhabitant [13].

\begin{tabular}{lcll}
\hline & $\begin{array}{c}\text { Energy demand } \\
(\mathrm{kWh} / \mathrm{d} \text { inh })\end{array}$ & $\begin{array}{l}\text { Type of } \\
\text { energy }\end{array}$ & Remarks \\
\hline Heating & 40 & Thermal & Coal, oil, gas \\
\hline Flights & 30 & Mechanical & Chemical energy (kerosene) \\
\hline Car & 40 & Mechanical & Chemical energy (fuel and diesel) \\
\hline Others & 90 & $\begin{array}{l}\text { Nearly all } \\
\text { electricity }\end{array}$ & $\begin{array}{l}\text { Comprises lighting, electric devices, } \\
\text { agriculture, energy that is needed to } \\
\text { produce all goods that are bought and their } \\
\text { transportation }\end{array}$ \\
\hline Total & 200 & & \\
\hline
\end{tabular}

(because there are too many different possibilities). Consequently, it is to differentiate between different forms of energy; thermal, mechanical or electricity, see Table 1.

The total of $200 \mathrm{kWh} / \mathrm{d}$ inh is necessary to ensure the current life-style. For comparison, one litre of fuel contains about $10 \mathrm{kWh}$ of energy; the daily demand per inhabitant corresponds to 201 of fuel.

The food should deliver daily about $3 \mathrm{kWh}$ [13] to the body of an average human. The production of this food needs energy as well as land. The energy demand for the food production is assessed with $15 \mathrm{kWh} / \mathrm{d}$ inh and is already included in Table 1 under "others" [13]. For the demand of agricultural land see the following Section 4.

\section{SPACE NEEDED FOR FOOD AND AGRICULTURAL PRODUCTS}

The total agricultural area in the world corresponds quite well to $2,000 \mathrm{~m}^{2} / \mathrm{inh}$ what is a square of $45 \times 45 \mathrm{~m}$. Practical experiments show that this enough to feed a person [14] - if the nutrition would be widely vegetarian. With the present high consumption of (industrial produced) meat, the need of land to feed the animals increases that threshold remarkably. As a consequence, to serve the meat eating society, the import of agricultural products from abroad is at a high level and increasing permanently. Supplementary land is grabbed at other places of the world, bringing the food production as well as their fair distribution to the world population out of balance.

For the final topic to investigate the space needed for the surrounding of a sustainable city two aspects can be noted:

- The existing agricultural area in Germany lays in fact in the range of $2,000 \mathrm{~m}^{2} / \mathrm{inh}$. In principle it can be self-sufficient. Products that need a warmer climate (bananas, citrons etc.) could be exchanged with wheat or potatoes.

- Currently Germany is far from that target, a drastic change in the manner of production (deindustrialized, decentralized, organic etc.) as well as in the German's consumption behaviour (less meat) would be necessary.

\section{SPACE NEEDED FOR RENEWABLE ENERGY SYSTEMS}

Renewable energies are coming (besides tide and heat from the hot core of the planet earth) in last consequence all from solar radiation. In Germany a square meter of land receives about $1,000 \mathrm{kWh}$ per year or $2.74 \mathrm{kWh} / \mathrm{d} \mathrm{m}^{2}$. The yearly offer would already cover the energy demand of one inhabitant for 5 days, in total $73 \mathrm{~m}^{2}$ of land would be sufficient. That very optimistic statement does not withstand a deeper investigation. Because of physical reasons renewable energy systems cannot transfer $100 \%$ of the solar radiation into another 
Table 2: Energy density (possible harvest) of renewable energy systems [13]. All values correspond to the solar offer in Germany of (in average) $2.74 \mathrm{kWh} / \mathrm{d} \mathrm{m}^{2}$.

\begin{tabular}{|c|c|}
\hline Renewable energy system & Energy density $\left(\mathrm{kWh} / \mathrm{d} \mathrm{m}^{2}\right)$ \\
\hline \multicolumn{2}{|l|}{ Electricity } \\
\hline PV modules & 0.4 \\
\hline Wind turbines onshore/offshore & $0.05 / 0.07$ \\
\hline \multicolumn{2}{|l|}{ Thermal energy } \\
\hline Wood pellets & 0.005 \\
\hline Solar collectors & 1.8 \\
\hline \multicolumn{2}{|l|}{ Chemical energy } \\
\hline Energy plants - biodiesel & 0.01 \\
\hline
\end{tabular}

energy form like electricity or mechanical energy; the possible harvest is described by the energy density, see Table 2.

To decide about practical application it must be noted that these renewable energy systems have besides their energy density supplementary specialities.

Electricity can easily be transported over big distances thus it can be produced everywhere. PV modules have the highest energy density (about $15 \%$ of the solar radiation is transferred) but cover the land completely; a second usage is hardly possible. A competition energy or food should be avoided; PV modules should be placed where agriculture is not possible. In first priority these are suitable surfaces in the cities, the buildings roofs, coverage of parking's etc. Wind turbines can only be placed with a certain distance to each other to avoid that the second one is in the wind shadow of the first one. That leads finally to the quite low energy density. But turbines are vertical, between them agricultural use is possible furthermore without problems. Because of dimension and noise wind turbines cannot be installed inside of cities, in first priority they should be placed in suitable areas in the surrounding or on the sea.

Thermal energy in form of heat cannot be transported over long distances and not be stored over long time, thermal losses would dominate. Thus, it must be produced on-site, in the cities and used in a short time. On the other hand, solar collectors have a very high energy density and should be applied inside of that limits. Another possibility is to produce (with sustainable forestry) material in the surroundings, to transport it into the city and to burn it there. But the energy density (of wood pellets, e.g.) is very low. Plants do accumulate only very few of the incoming solar radiation as material in their own body.

Chemical energy can be gained with special energy plants (soya, rape, palm oil, etc.). Besides the low energy density is a further problem the increasing occupation of land for the production; a competition with food should be avoided, there are other sources for regenerative energy production.

\section{STRATEGIES TO REDUCE ENERGY DEMAND AND TO COVER IT WITH RENEWABLES}

For the transfer of the society into a sustainable one three different basic strategies are possible, they are noted here only in regard to energy but their philosophy is valid for all other aspects like land use and resources:

(a) No change in the current lifestyle and replace the fossil energy by renewable one. 
(b) Reduce the energy demand by increasing the efficiency of the systems. Replace the remaining (fossil) energy demand by renewable energy. Strategies a) and b) are the pure technical answer.

(c) Change the lifestyle into a less energy consuming one. That change can be realized only if it will be accepted in the society. For this, a discussion is necessary, what are our real needs and what do we need to satisfy them. Ideally nobody should have the feeling that one loses quality of life. Replace the remaining (fossil) energy demand by renewable energy.

Strategy (a) is the most comfortable one regarding our lifestyle. Germany has an area of $357,000 \mathrm{~km}^{2}$ and 85 million inhabitants; that corresponds 0.42 ha of land per inhabitant. If the current life-style is taken like it is the energy demand would be $200 \mathrm{kWh} / \mathrm{d}$ inh. If that amount should be replaced even by the most effective renewable energy system, PV modules (it is obvious that this is not possible, but details are neglected for a moment, the target is to gain an impression about the minimal demand of land for renewable energies if strategy (a) would be the only one), $200 \times 85,000,000 / 0.4 / 1,000,000=42,500 \mathrm{~km}^{2}$ of land would be necessary to serve Germany. That area corresponds nearly to the area for settlement and transportation (15\% of Germany, see Table 4$)$ - that land is not available supplementary. If the whole demand is assumed to be covered by wind turbines onshore already $340,000 \mathrm{~km}^{2}$ would be necessary, that is about the whole area of Germany - but we cannot cover it completely.

Evidently, strategy (a) alone leads not to the target, strategies (b) and perhaps (c) are necessary. In fact, an efficiency revolution is possible in two fields, heating and land based transportation (see Table 3).

Table 3: Possible reduction of energy demand of an average middle European inhabitant [13] and replacement by renewable energies without changing lifestyle. The reduction is exclusively reached by higher efficiency, for the situation "before" see Table 1.

\begin{tabular}{|c|c|c|c|c|}
\hline & \multicolumn{2}{|c|}{$\begin{array}{l}\text { Energy demand } \\
(\mathrm{kWh} / \mathrm{d} \text { inh })\end{array}$} & \multirow[t]{2}{*}{ Reduction } & \multirow[t]{2}{*}{ Renewable energy } \\
\hline & Before & After & & \\
\hline Heating & 40 & 10 & Thermal insulation of buildings & $\begin{array}{l}\text { Thermal (wood } \\
\text { pellets, bio gas } \\
\text { etc.) }\end{array}$ \\
\hline Flights & 30 & 30 & Only strategy (c) & $\begin{array}{l}\text { Chemical (bio } \\
\text { kerosene) }\end{array}$ \\
\hline Car & 40 & 16 & Transfer to electrical machines & Electricity \\
\hline Others & 90 & 80 & $\begin{array}{l}\text { Transfer to electrical machines for } \\
\text { transportation of products, LED for } \\
\text { lighting and mainly strategy c) }\end{array}$ & Electricity \\
\hline Total & 200 & 136 & & \\
\hline
\end{tabular}

The heating demand can be reduced drastically down to $1.5 \mathrm{kWh} / \mathrm{d}$ inh by constructing new buildings in the passive house standard, with high thermal insulation and (during cold seasons) mechanical ventilation with heat recovery. Building refurbishment cannot reach in general the same standard but should be near as possible to it. It might be that in total $10 \mathrm{kWh} / \mathrm{d}$ inh can be reached for all buildings, an increase in efficiency by a factor of 4 . A 
European directive [15] brought this initiative already into power, all new erected buildings have to be nearly-zero-energy-buildings and the building stock shall be refurbished.

Combustion machines in cars and trucks have a very bad efficiency tank to wheel of only about $15 \%$. Electrical machines are much more efficient but cars may be heavier because of the load of the batteries. Latest electrical cars on the market need finally about $40 \%$ of the energy of combustion ones, an increase in efficiency by a factor of 2.5. And, supplementary, fossil fuel can be replaced by renewable electricity.

The energy demand for transportation of products would be reduced in the same way. Also, the replacement of older systems by modern LED would decrease the demand for lighting. In total it can be assessed that the demand for "others" in Table 2 can be reduced to $80 \mathrm{kWh} / \mathrm{d}$ inh.

Electricity and thermal energy do not directly present an alternative to replace the chemical energy that is used for airplanes. The only way seems to be the production of bio kerosene in form of hydrogen or methane, the efficiency electricity to gas (electrolysis) is about $50 \%$, the energy density would be $50 \%$ of the values for electricity in Table 2 thus $0.2 \mathrm{kWh} / \mathrm{d} \mathrm{m}^{2}$ for PV modules and $0.025 / 0.035 \mathrm{kWh} / \mathrm{d} \mathrm{m}^{2}$ for wind turbines on-/offshore.

Table 3 shows that by increasing efficiency a reduction of the energy demand by about one third is possible. But, obviously, even for that the available land is not sufficient to produce all the energy as renewable one. The conclusion is that without strategy (c), a change in the lifestyle, the target cannot be reached.

\section{THE SURROUNDING}

Table 3 shows that after the transition to higher efficiencies for heating and transportation the demand per inhabitant would be $10 \mathrm{kWh} / \mathrm{d}$ thermal energy (heating) and $156 \mathrm{kWh} / \mathrm{d}$ electricity $(2 \mathrm{kWh}$ electricity are needed to produce $1 \mathrm{kWh}$ of bio kerosene thus $2 \times 30+16$ $+80)$.

For deeper investigation of the role of the surrounding it is helpful to return to the findings of Section 2. Here it was stated that an urban density of $100 \mathrm{inh} / \mathrm{ha}$ is a good precondition for liveability as well as for sustainability. The $10,000 \mathrm{~m}^{2}$ of that hectare are dedicated to different usages, for the buildings $3,000 \mathrm{~m}^{2}$ are available. It can be assumed that $50 \%$ of the corresponding roof area $\left(1,500 \mathrm{~m}^{2}\right)$ have a good orientation to be covered with PV modules. That leads to the request that the buildings should have about the same height and number of storeys to avoid that the roofs shade each other and cannot be used for PV modules. Again, the inner part of Paris is a good model, but also Masdar city [16] as an example of modern architecture and urban planning. With these $1,500 \mathrm{~m}^{2}$ of PV modules $600 \mathrm{kWh} / \mathrm{d}$ could be earned what satisfies the energy demand of about four of the 100 inhabitants. Further production of energy (mini wind turbines, mini biogas etc.) and food (urban gardening) are very welcome and have an absolutely positive social impact but would not remarkably contribute to cover the demand. All the rest of energy and food has to be produced in the surrounding and brought to the city.

Like already mentioned in Section 6, in Germany per inhabitant 0.42 ha land are available, for 100 inhabitants 42 ha. Table 4 shows the land use as well as the available area for 100 inhabitants. For food the need of 2,000 $\times 100 / 10,000=20$ ha (see Section 4, widely vegetarian) is available. If for energy is assumed (a bit too optimistic) that the whole agricultural area could have a double use with wind turbines and that the forest is used for the renewable production of wood pellets only about two third of the energy demand could be covered. For the remaining third there is no further land in Germany. 
Table 4: Land use of Germany in percent and corresponding area for 100 inhabitants. A possible second use for renewable energy production and the corresponding generation are shown further as well the comparison with the demand after the increased efficiency in heating and transportation.

\begin{tabular}{|c|c|c|c|c|c|}
\hline \multirow[t]{2}{*}{ Land use } & \multirow[t]{2}{*}{$\%$} & \multirow[t]{2}{*}{$\begin{array}{l}\text { Area for } 100 \\
\text { inh (ha) }\end{array}$} & \multirow[t]{2}{*}{ Second use } & \multicolumn{2}{|c|}{$\begin{array}{l}\text { Energy generation } \\
(\mathrm{kWh} / \mathrm{d})\end{array}$} \\
\hline & & & & Electricity & Thermal \\
\hline Agriculture & 50 & 21 & $\begin{array}{l}\text { Wind turbines } \\
\text { onshore }\end{array}$ & 10,500 & \\
\hline Forest & 30 & 12.6 & Wood pellets & & 630 \\
\hline $\begin{array}{l}\text { Settlement and } \\
\text { transportation }\end{array}$ & 15 & $\begin{array}{l}1 \text { (city) }+5.3 \\
\text { (surrounding) }\end{array}$ & $\begin{array}{l}\text { PV modules on } \\
\text { building's roofs }\end{array}$ & 600 & \\
\hline Water bodies & 2.5 & 1.05 & & & \\
\hline Others & 2.5 & 1.05 & & & \\
\hline \multirow[t]{3}{*}{ Total land } & 100 & 42 & Total generation & 11,100 & 630 \\
\hline & & & Total demand & 15,600 & 1,000 \\
\hline & & & Not covered & $35 \%$ & $37 \%$ \\
\hline
\end{tabular}

It must be noted that the scenario presented here in Section 7 is a view into a possible future but even then the available land is overstressed by a factor of about 1.5. The real situation is still far from that. The current ecological footprint of Germany (and all other comparable countries) is estimated between 2.5 and 3 [17].

Fig. 2 illustrates the situation for the capital Berlin. It has 3.5 million inhabitants. The available land $(0.42 \mathrm{ha} / \mathrm{inh})$ comprises $14,700 \mathrm{~km}^{2}$ or a circle with a radius of $68 \mathrm{~km}$. To have a sustainable Berlin all food and all energy have to be produced inside of that range. The reality is far from it, even after an increase in efficiency in heating and transportation another $50 \%$ of land would be necessary for the resulting reduced energy generation, what would correspond to a circle with a radius of $83 \mathrm{~km}$. That land is not available, it would already overlap with the equivalent circles of the bigger neighbour cities in Germany and Poland (Szczecin, Magdeburg, Leipzig).

\section{CONCLUSIONS}

In literature and speeches the term sustainable city is widely used. Often it concentrates only on the city scale, without detailed investigation from where the missing renewable energy, food and products should come. Initiatives on-site like urban gardening, mini wind turbines etc. are very welcome but can by far not cover the need.

To be justice to sustainability it is necessary to regard the topic on a larger scale, the city and its surrounding. Only here the city's remaining demand for energy and food and partly other products can be fulfilled.

The main target of this paper is to show that there is another important limited resource that has to be regarded on the development to sustainability - the available land. Food production and especially the harvest of renewable energies need big areas; their amount can be determined or in minimum estimated. In countries with high population density like Germany it might be the dominant resource that determines the amount of food and energy that can be provided to the city.

The investigation shows that with the present lifestyle surrounding land would be necessary that corresponds to a multiple of Germany. Germany and its cities are far from 


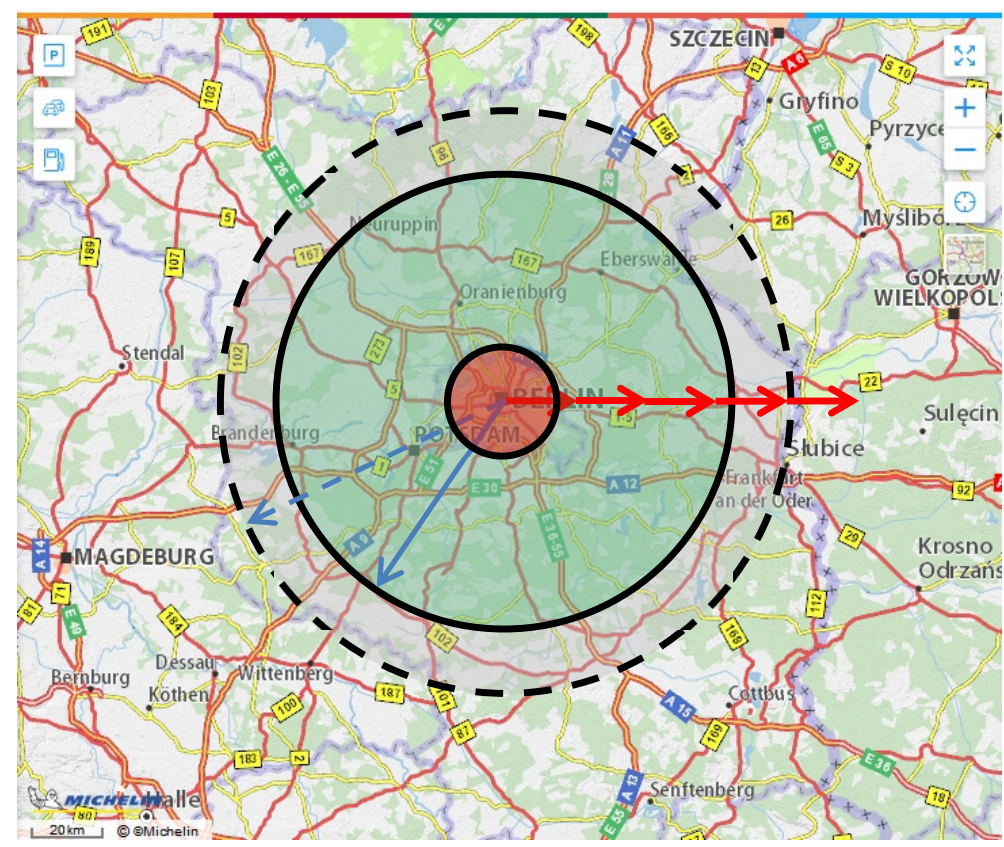

Figure 2: Space availability for sustainable Berlin. The city corresponds to a circle with a radius of $10.5 \mathrm{~km}$ (red), the available land a circle with $68 \mathrm{~km}$ radius (green, arrow and circle with continuous line). Inside of that range all food and all energy should be produced for a sustainable city. Even after an increase of efficiency in heating and transportation supplementary another $50 \%$ of land would be necessary, corresponding to a circle with a radius of $83 \mathrm{~km}$ (grey, arrow and circle with dotted line). The red arrows mark a scale of $20 \mathrm{~km}$ distances. (Source: Map based on [18].)

being sustainable (the same holds for all other developed countries too). Even with a strong increase in efficiency for heating and transportation the need of land would correspond to 1.5 times Germany.

To reach the target and to become really sustainable, a sequence of concerted measures is necessary. The technical part is called in Rifkin [19] the third industrial revolution (this term is very pleasant, a revolution is something that includes a strong movement forwards and a strong change; it sounds much better than an adaptation to climate change and, in fact, it is a revolution).

In first priority, the demand side is to reduce by increase of efficiency and change of lifestyle:

- Food: Widely vegetarian nutrition, less meat. Avoid industrial production.

- Transportation: Replace combustion machines by electrical machines. Less flights, more railways. Less car, more public transportation, bicycles, walking. Avoid, if there is a local alternative, products from far away.

- Heating: Thermal insulation of building stock. New buildings are erected as nearlyzero-energy-buildings.

- $\quad$ Lighting: Replace older systems by LED. 
In the second priority (but to realize simultaneously!) replace the fossil energy production by renewable one:

- Change the structure of generation and grid from a centralized one into a decentralized one where energy is produced and used at all places at the same time.

- PV modules have the highest energy density. Their best place is on the suitable areas of the building's roofs in the cities. To avoid shadowing, buildings should have about the same height and number of storeys.

- Wind turbines can be installed in the surroundings, a double use with agriculture is possible.

- For the remaining demand of chemical energy electrolysis (electricity to gas, hydrogen or methane) can be used.

- Forests can be used for sustainable production of material that can be burned to heat buildings.

Roughly, Germany as well as the developed countries have to reduce their demand for energy and land by a factor of about three. About one third can be saved by an increase in efficiency, especially in heating and transportation. Another third has to be contributed by a change in the lifestyle (with the feeling that the basic needs are in minimum as satisfied as before). The last third can be covered be renewable systems in the surroundings of the city. But to reach that, each potential for renewable energy production must be used. That means, that we should see PV modules on all roofs, wind turbines everywhere in the landscape etc. Only then we will have a successful change to a sustainable society.

\section{REFERENCES}

[1] The Basque Declaration. http://www.sustainablecities.eu/endorse-the-basquedeclaration/. Accessed on: 27 Dec. 2020.

[2] World Future Council and HafenCity University Hamburg (HCU) Commission on cities and climate change. Regenerative Cities, 2010.

https:/www.worldfuturecouncil.org/wp-content/uploads/2016/01/WFC_2010_ Regenerative_Cities.pdf. Accessed on: 27 Dec. 2020.

[3] Cording, E., Wohnen in der Dichte, Bauliche Bedingungen der Privatheitsregulation im Außenraum verdichteter Wohnformen, PhD thesis, Universität Oldenburg, 2007. https://oops.uni-oldenburg.de/id/eprint/15. Accessed on: 27 Dec. 272020.

[4] Newman, P.W.G. \& Kenworthy, J., Gasoline consumption and cities. Journal of the American Planning Association, 55, pp. 24-37, 1989.

[5] Lefèvre, B., Urban transport energy consumption: Determinants and strategies for its reduction, 2009. https://journals.openedition.org/sapiens/914. Accessed on: 27 Dec. 2020.

[6] Dietrich, U., The pleasure of walking in a neighbourhood: The pedestrian route network and its fractal dimension as a tool for the assessment of the right balance between chaos and order. To be published.

[7] Boeing, J., Measuring the complexity of urban form and design. https://www.researchgate.net/publication/316711249_Measuring_the_Complexity_of Urban_Form_and_Design, Accessed on: 20 Dec. 2020.

[8] Google Maps. https://www.google.de/maps/. Accessed on: 19 Dec. 2020.

[9] Salat, S., Cities and forms. On Sustainable Urbanism, Hermann: Paris, 2011. 
[10] Frank, L.D., Sallis, J.F., Saelens, B.E., Leary, D.L., Cain, B.K., Conway, T.L. \& Hess, P.M., The development of a walkability index: Application to the neighborhood quality of life study. British Journal of Sports Medicine, 44(13), pp. 924-933, 2010.

[11] Borchard, K., Wie viel Fläche braucht der Mensch? REFINA Conference, Bonn, 2000.

[12] Freiburg Rieselfeld. https://www.freiburg.de/pb/,Lde/208560.html. Accessed on: 28 Dec. 2020.

[13] MacKay, D., Without the hot air, 2015. https://withouthotair.com/. Accessed on: 29 Dec. 2020.

[14] Deutschlandfunk Kultur, Wie viel Anbaufläche braucht ein Mensch. https://www.deutschlandfunkkultur.de/weltacker-experiment-wie-viel-anbauflaechebraucht-ein.976.de.html?dram:article_id=333459. Accessed on: 28 Dec. 2020.

[15] Directive 2010/31/EU of the European Parliament and of the Council of 19 May 2010 on the energy performance of buildings. https:/eur-lex.europa.eu/legal-content/ EN/ALL/;ELX_SESSIONID=FZMjThLLzfxmmMCQGp2Y1s2d3TjwtD8QS3pqdkh XZbwqGwlgY9KN!2064651424?uri=CELEX\%3A32010L0031. Accessed on: 30 Dec. 2020.

[16] Masdar city. https://masdar.ae/en/. Accessed on: 31 Dec. 2020.

[17] The ecological footprint. https://www.thenaturalstep.de/challenge/ecologicalfootprint/. Accessed on: 31 Dec. 2018.

[18] ViaMichelin. https://www.viamichelin.com/. Accessed on: 31 Dec. 2020.

[19] Rifkin, J., The Third Industrial Revolution, Palgrave \& MacMillan: New York, 2011. 